\title{
Cytogenetic events in the endosperm of amphiploid Avena magna $\times A$. longiglumis
}

\author{
Paulina Tomaszewska $^{1}$ (D) Romuald Kosina ${ }^{2}$ (D)
}

Received: 13 January 2021 / Accepted: 19 May 2021 / Published online: 31 May 2021

(c) The Author(s) 2021

\begin{abstract}
This study analysed cytogenetic events occurring in the syncytial endosperm of the Avena magna H. C. Murphy \& Terrell $\times$ Avena longiglumis Durieu amphiploid, which is a product of two wild species having different genomes. Selection through the elimination of chromosomes and their fragments, including those translocated, decreased the level of ploidy in the endosperm below the expected $3 n$, leading to the modal number close to $2 n$. During intergenomic translocations, fragments of the heterochromatin-rich C-genome were transferred to the $\mathrm{D}$ and $\mathrm{Al}$ genomes. Terminal and non-reciprocal exchanges dominated, whereas other types of translocations, including microexchanges, were less common. Using two probes and by counterstaining with DAPI, the A. longiglumis and the rare exchanges between the D and Al genomes were detected by GISH. The large discontinuity in the probe labelling in the $\mathrm{C}$ chromosomes demonstrated inequality in the distribution of repetitive sequences along the chromosome and probable intragenomic rearrangements. In the nucleus, the spatial arrangement of genomes was non-random and showed a sectorial-concentric pattern, which can vary during the cell cycle, especially in the less stable tissue like the hybrid endosperm.
\end{abstract}

Keywords Amphiploid $\cdot$ Avena $\cdot$ Chromosome rearrangements $\cdot$ Genome domains $\cdot$ Nuclear disorders

\begin{tabular}{|c|c|}
\hline \multicolumn{2}{|c|}{ Abbreviations } \\
\hline PI & Propidium iodide \\
\hline CTAB & Cetyltrimethylammonium bromide \\
\hline dUTP & $2^{\prime}$-Deoxyuridine, 5'-triphosphate \\
\hline SSC & Saline sodium citrate \\
\hline FITC & Fluorescein isothiocyanate \\
\hline GISH & Genomic DNA in situ hybridisation \\
\hline BFB & Breakage/fusion/bridge cycle \\
\hline $\mathrm{SCO}$ & Somatic crossing over \\
\hline $\mathrm{Am} \times \mathrm{Al}$ & $\begin{array}{l}\text { Avena magna } \mathrm{H} \text {. C. Murphy \& Terrell } \times \text { Avena } \\
\text { longiglumis } \text { Durieu amphiploid }\end{array}$ \\
\hline
\end{tabular}

Romuald Kosina

romuald.kosina@uwr.edu.pl

1 Institute of Experimental Biology, University of Wrocław, Wrocław, Poland

2 Institute of Environmental Biology, University of Wrocław, Przybyszewskiego 63, 51-148 Wroclaw, Poland

\section{Introduction}

Endosperm, which is the storage tissue of grass caryopsis, plays an important role in human nutrition, and hence, should be thoroughly analysed. Many grass species, including cereals, have evolved through the processes of hybridisation and polyploidisation (Grant 1981). In young hybrids, endosperm development is highly unstable as in Triticale (Kaltsikes 1973; Peña et al. 1982) or oats (Tomaszewska and Kosina 2018) and is correlated with the cytogenetic behaviour of the plant. In addition, the low level of telomerase activity in the endosperm, which was first observed in barley and maize, has been found to affect the stability of telomeres and result in cytogenetic aberrations (Kilian et al. 1998). In the young pistils of Arabidopsis Heynh., shortened telomeres were shown to induce the breakage/fusion/bridge (BFB) cycle (Siroky et al. 2003). Such cytogenetic behaviour was also observed in human cancer cells presenting of telomere instability (Lo et al. 2002).

Most studies available in the literature on cytogenetic data are related only to root tissues and not endosperm. Thus, for instance, in the roots of Avena sativa L., intergenomic translocations, which have been visualised as large exchanges using genomic DNA in situ hybridisation (GISH) by Chen 
and Armstrong (1994), but as sites of point hybridisation by Jellen et al. (1994), proved that even small translocations can change the genome status. The level of cytogenetic disorders can be extremely high, as was observed in a single Elymus farctus (Viv.) Runemark ex Melderis plant (Heneen 1963). There is a common agreement that heterochromatin is involved in these changes, and in the species mentioned above, large blocks of terminal heterochromatin have been discovered (Endo and Gill 1984). Furthermore, it has been proved that the sites of C-banding (heterochromatin) and translocation breaks coincide in the $\mathrm{D}$ (previously recognised as the $\mathrm{A}$ genome) and $\mathrm{C}$ genomes of Avena maroccana Gand. (Jellen et al. 1994). The C genome is highly heterochromatic (Fominaya et al. 1988b), and such a chromosome structure can contribute to translocation events. The $\mathrm{C}$ genome of A. magna also has heterochromatin dispersed along the chromosomes (Shelukhina et al. 2007), while the A genomes of various diploid oats and highly homologous D genome in hexaploids have less heterochromatin localised mainly at telomeres (Badaeva et al. 2005; Fominaya et al. 1988a; Linares et al. 1998). This intergenomic difference in the amount of heterochromatin can significantly affect the dynamics of chromosomal rearrangements under the conditions of hybridity. In addition, during the evolution of CCDD tetraploids (previously assigned to AACC), both C and D genomes were altered to different degrees, especially the $\mathrm{C}$ genome (Drossou et al. 2004).

The parental species of the A. magna H. C. Murphy \& Terrell $\times$ Avena longiglumis Durieu amphiploid are meiotically compatible in the crossing process exhibiting partial sterility (Loskutov 2001), but the result of their crossover is influenced by the ecotype of A. longiglumis (Rajhathy 1971). The genomic status of the amphiploid is determined by the $\mathrm{C}$ genome and two different highly homologous genomes $\mathrm{Al}$ and $\mathrm{D}$. In the hybrids formed by crossing Avena strigosa Schreb. (AsAs genomes), Avena eriantha Durieu (CpCp genomes), and A. magna (CCDD genomes, previously AACC), the meiotic division is characterised by a poor pairing of chromosomes, which can be related to translocation variability rather than the lack of chromosome homology (Leggett 1998; Nikoloudakis and Katsiotis 2015). The last statement is very important due to the role played by small and large translocations in stabilising the reproduction system of young polyploid hybrid forms and their speciation.

The present molecular studies on oat genomes proved that the A genomes of A. maroccana, A. magna, and A. muphyi have to be considered as D genome (Yan et al. 2016; Yan et al. 2021; Paulina Tomaszewska, pers. comm.). This was also corroborated by the similarity between the chromosomes $10 \mathrm{~A}$ 'magna' and 21D 'sativa' (Fominaya et al. 2017). The principal coordinates analysis showed that $A$. eriantha and A. longiglumis are closer to CCDD (previously AACC) oat tetraploids than other AA diploids (Yan et al. 2016). Both species were accepted as ancestral during the evolution of AACC (CCDD) tetraploids and AACCDD hexaploids (Chew et al. 2016). The exceptional role played by $A$. longiglumis in the oat evolution was also studied by $\mathrm{Fu}$ (2018). The author analysed $\mathrm{cp}$ and $\mathrm{mt}$ genomes and proved that $A$. longiglumis was a maternal component that created Avena insularis Ladiz. (AACC genomes; currently CCDD, Yan et al. 2021), and subsequently a paternal species with A. insularis as a maternal species in the evolution of the AACCDD species. A. insularis and A. magna were recognised as closely related taxa (Shelukhina et al. 2007; Yan et al. 2021). Thus, in the light of the above data, the research of a 'magna-longiglumis' hybrid unit and its endosperm can significantly supplement the knowledge about the biology of the cereal developing large caryopses. However, distinguishing three different genomes in this hybrid, including $\mathrm{C}$ genome and two highly homologous $\mathrm{Al}$ and $\mathrm{D}$ genomes, becomes a challenge, and potentially requires two different genomic DNA probes used for genomic in situ hybridization: $\mathrm{Cp}$ (from $A$. eriantha, A. clauda or A. pilosa), and $\mathrm{Al}$ (from A. longiglumis) or As (from A. nuda, A. strigosa, A. brevis, A. atlantica or A. wiestii).

GISH analyses have revealed that in the sexual hybrids, different genomes are not randomly distributed in the nucleus (Schwarzacher et al. 1989). This non-random architecture of chromatin is maintained throughout the cell cycle (Leitch et al. 1991). Genome separation has also been observed in somatic hybrids, but it was found that there is a change in the pattern of separation from segmental to radial (Gleba et al. 1987). In the case of grass endosperm, the genomes were found to change the arrangement from sectorial to concentric in nuclei approaching apoptosis (Tomaszewska and Kosina 2013). It has been shown that the architecture of genome domains correlates with genes expression (Bennett 1984; Heslop-Harrison 1990). However, the reference data on nuclear architecture in the endosperm are not common.

The endosperm is a complex object to conduct a cytogenetic analysis compared to other tissues due to less chromatin condensation as shown in Arabidopsis (Baroux et al. 2007). For this reason, identifying chromosome rearrangements and other cytogenetic aberrations is very challenging. Thus, the overall purpose of this paper is to enrich the available data on endosperm cytogenetics in cereals. More specifically, it focuses on the identification of genomes in the hybrid endosperm and establishing the relationships between them by determining the level of genome rearrangement, with an emphasis on intergenomic translocations. 


\section{Materials and methods}

\section{Plant material}

To perform a cytogenetic analysis of the free-nuclear syncytium of the oat amphiploid A. magna $\mathrm{H}$. C. Murphy \& Terrell $\times$ A. longiglumis Durieu $(\mathrm{Am} \times \mathrm{Al})$ and its parental species (taxonomic units) young embryo sacs were sampled from plants, that were cultivated on small plots in the grass collection (Wroclaw, SW Poland), which were maintained by R. Kosina. During the plot experiments, the plants were grown under the same soil-climatic conditions. For each taxonomic unit, 45 embryo sacs were mounted on 15 microscopic slides by pooling three on each. Thus, the study material can be considered as a one-way classification in a completely randomised design. Finally, clear stages of mitosis were selected on microscopic slides as small samples $(n<30$ or larger, see Table 2$)$ for photographic documentation and quantification. The following oat accessions were used in the study. Level of ploidy, genomes, donor and accession number are given in brackets. The botanical nomenclature was applied according to: https://npgsweb.ars-grin.gov/gringlobal/taxon/taxonomyse arch.aspx, http://www.theplantlist.org/

Avena magna $\mathrm{H}$. C. Murphy \& Terrell $\times$ Avena longiglumis Durieu (6x, genomes CCDDAlAl, NSGC, CIav9364)

Avena magna $\mathrm{H}$. C. Murphy \& Terrell (4x, genomes CCDD, VIR, 1786)

Avena longiglumis Durieu ( $2 x$,genomes AlAl, NSGC, PI 367,389)

Avena eriantha Durieu ( $2 x$, genomes CpCp, NSGC, PI 657,576)

Avena nuda L. (2x, genomes AsAs, NSGC, CIav 9010)

Genomic DNAs from A. eriantha and A. nuda were used to develop GISH probes.

According to some plant checklists, both names Avena maroccana Gand. and Avena magna H. C. Murphy \& Terrell can be considered equivalent. Therefore, we sometimes applied the name $A$. maroccana when citing publications where that name was used.

\section{Cytogenetic preparation}

Mitotic spreads were prepared from the endosperm at the syncytial stage. The endosperm was isolated from young caryopses between 2 and 3 days after pollination, and fixed in ethanol:acetic acid (3:1) solution. The fixed endosperm was washed in an enzyme buffer $(10 \mathrm{mM}$ citric acid/sodium citrate) for $15 \mathrm{~min}$, and digested with enzyme mixture containing $0.3 \%$ cellulase from Aspergillus niger, $0.3 \%$ pectolyase from Aspergillus japonicus, and 0.3\% cytohelicase from Helix pomatia in the enzyme buffer for $45 \mathrm{~min}$ at $37{ }^{\circ} \mathrm{C}$. The digested endosperm was washed again in the enzyme buffer for $15 \mathrm{~min}$ and squashed in $45 \%$ acetic acid. Coverslips were removed after the slides were frozen with liquid nitrogen. Then the slides were air-dried and used for the in situ hybridization procedure.

\section{Probe preparation}

Avena eriantha and $A$. nuda were chosen to obtain probes of the genomic DNAs for GISH analyses. Genomic DNA from $A$. eriantha ( $\mathrm{CpCp}$ genomes) and some its sequences were commonly used to detect the genome $\mathrm{C}$ in other oats and their hybrid progeny (Hayasaki et al. 2000; Linares et al. 2000; Ueno and Morikawa 2007). In this study, the probe of the genome $\mathrm{Cp}$ was used to detect $\mathrm{C}$ genome in A. magna and its amphiploid. A. nuda was recognised as closely related to $A$. strigosa, both having AsAs genomes (Yan et al. 2016). Some repetitive sequences of the genome As appeared to be common in the genomes A and D in oat hexaploids (Katsiotis et al. 2000; Linares et al. 1998), therefore, the probe of the $A$. nuda genome was also used in the GISH analysis in this study.

Genomic DNAs were extracted from fresh leaves of $A$. eriantha and Avena nuda using a standard method based on cetyltrimethylammonium bromide (CTAB) (Doyle and Doyle 1990) with minor modifications. The obtained DNAs were used as probes for GISH. The DNA of A eriantha was labelled with tetramethylrhodamine-5-dUTP and that of $A$. nuda with digoxigenin-11-dUTP by nick translation, using a commercially available kit (Roche). After labelling, ethanol precipitation was performed. The DNA pellets thus obtained were washed with $70 \%$ ethanol prior to drying and resuspended in water.

\section{Genomic in situ hybridisation}

GISH was carried out as described by Schwarzacher et al. (1989) with minor modifications. Prior to the procedure, the slides were fixed in ethanol:acetic acid (3:1) solution for $10 \mathrm{~min}$, and washed two times in $96 \%$ ethanol (10 min each). The slides were air-dried and treated with $0.1 \mathrm{mg} \cdot \mathrm{ml}^{-1}$ of DNase-free RNase A in $2 \times \mathrm{SSC}(0.3 \mathrm{M} \mathrm{NaCl}, 0.03 \mathrm{M}$ sodium citrate, $\mathrm{pH} 7$ ) for $1 \mathrm{~h}$ at $37{ }^{\circ} \mathrm{C}$. Then, the slides were washed with $2 \times \mathrm{SSC}$ for $15 \mathrm{~min}$ and $0.01 \mathrm{M} \mathrm{HCl}$ for $5 \mathrm{~min}$ at room temperature (RT). After washing, $200 \mu \mathrm{lof} 5 \mu \mathrm{g} \cdot \mathrm{ml}^{-1}$ pepsin in $0.01 \mathrm{M} \mathrm{HCl}$ was applied to each slide, and the slides were incubated for $15 \mathrm{~min}$ at $37^{\circ} \mathrm{C}$. Next, the slides were washed twice with $2 \times \operatorname{SSC}(5$ min each) and incubated in freshly prepared $4 \%$ paraformaldehyde for $10 \mathrm{~min}$ at RT. The slides were again washed twice with $2 \times \operatorname{SSC}(5 \mathrm{~min}$ each), dehydrated through a series of ethanol solutions (70\%, $85 \%, 96 \% ; 10$ min each) and finally air-dried. 
A hybridisation mixture consisting of $50 \%$ deionised formamide, $10 \%$ dextran sulphate, $1 \%$ sodium dodecyl sulphate, $2 \times \mathrm{SSC}$, two DNA probes $\left(2 \mathrm{ng} \mu \mathrm{l}^{-1}\right.$ each) and

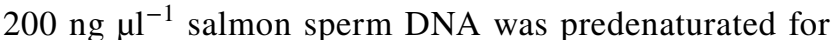
$10 \mathrm{~min}$ at $75{ }^{\circ} \mathrm{C}$ and stabilised on ice for $10 \mathrm{~min}$. Then, $40 \mu \mathrm{l}$ of the hybridisation mixture was applied to each slide, and the slides were covered with plastic coverslips. The chromosomes and probes were denatured together in a thermocycler (PTC-100TM; MJ Research, Inc.) using a special adapter (The Slide Griddle ${ }^{\mathrm{TM}}$, Model SG96P; MJ Research, Inc.) for $7 \mathrm{~min}$ at $75{ }^{\circ} \mathrm{C}$. The temperature was gradually decreased during hybridisation. Hybridisation was carried out overnight in a hybridisation oven (Biometra, OV3) at $37^{\circ} \mathrm{C}$. The coverslips were removed and the slides were washed with $2 \times$ SSC for 2 min, $20 \%$ formamide in $0.1 \times \mathrm{SSC}$ twice $(5 \mathrm{~min}$ each) and $2 \times \mathrm{SSC}$ three times (8 min each). All the post-hybridisation washes were carried out at $42{ }^{\circ} \mathrm{C}$. The slides were incubated in $4 \times \mathrm{SSC} / 0.2 \%$ Tween 20 for 5 min at RT prior to detection, and then in 5\% bovine serum albumin (BSA) in detection buffer for $15 \mathrm{~min}$ at $37^{\circ} \mathrm{C}$. The probe labelled with digoxigenin was detected with fluorescein isothiocyanate (FITC)-conjugated sheep anti-digoxigenin antibody. Then, $50 \mu \mathrm{l}$ of detection solution (final concentration of antibody $3 \mu \mathrm{g} \cdot \mathrm{ml}^{-1}$ ) was applied to each slide and covered with a plastic coverslip. The slides were incubated in a moist chamber for $90 \mathrm{~min}$ at $37{ }^{\circ} \mathrm{C}$. Then, each slide was washed three times in $4 \times \mathrm{SSC} / 0.2 \%$ Tween 20 at $42{ }^{\circ} \mathrm{C}$ for $8 \mathrm{~min}$, dehydrated through a series of ethanol solutions $(70 \%, 85 \%, 96 \% ; 1$ min each) and finally air-dried. The slides were counterstained with DAPI (4',6-diamidino-2-phenylindole, $2 \mu \mathrm{g} \cdot \mathrm{ml}^{-1}$ ) or PI (propidium iodide) in antifade solution (AF1, Citifluor). According to Schwarzacher and Heslop-Harrison (2000), these conditions allow hybridisation between DNAs that share $85 \%$ sequence identity (stringency) and to assess genome homology at this level.

\section{Microscopy}

The slides were examined under an Olympus BX-60 epifluorescence microscope (Hamburg, Germany), and images were taken with an Olympus E-520 camera (Olympus Imaging Europa GMBH, Hamburg, Germany).

\section{Results}

\section{Cytogenetic disorders}

Various cytogenetic disorders were observed in both amphiploid and its parental species (Table 1). The hyperploid metaphases occurred at a low frequency in the amphiploid and A. longiglumis, but they were not observed in Avena magna
Table 1 Types of cytogenetic disorders in the free-nuclear endosperm of the amphiploid and its parental species

\begin{tabular}{llllll}
\hline Amphiploid and parental species & \multicolumn{7}{l}{ Types of disorders } \\
\cline { 2 - 7 } & HP & BR & MSC & MN & IN \\
\hline A. magna $\times$ A. longiglumis & 7.7 & 0 & 7.7 & 2 & 0 \\
A. magna & 0 & 52.4 & 23.5 & 2 & 5.9 \\
A. longiglumis & 7.7 & 25.0 & 0 & 1 & 15.4 \\
\hline
\end{tabular}

$H P$ hyperploid prophases, metaphases and anaphases; $B R$ bridges; $M S C$ mis-segregated (precocious or delayed) chromosomes; $M N$ modal number of micronuclei per one nucleus; $I N$ irregular shape of nuclei. Except $M N$, other values are given in percent

H. C. Murphy \& Terrell. The chromosomal bridges in anaphases (Fig. 1b, f) and telophases support the conclusion that the BFB cycle can occur in the free-nuclear syncytium. The bridges in anaphases and telophases were observed at a high frequency, and A. magna was twice as likely to develop them compared to $A$. longiglumis. On the other hand, bridges were not observed in the amphiploid, while a low mitotic index was noted: only six out of 45 young caryopses showed anaphases and telophases. This indicates that analysis of more seeds could reveal the formation of bridges. The missegregated (precocious or delayed) single chromosomes or their groups were noted at a low frequency in the amphiploid, and they were more frequent in A. magna. Chromosome elimination (Fig. 1b) was not observed in A. longiglumis. The mis-segregated chromosomes or their fragments (Fig. 1a) can next form condensed micronuclei (Fig. 1c, e, $\mathrm{g}, \mathrm{h})$. In amphiploid and its parental species, micronuclei were noted in every syncytial endosperm. The maximum number of micronuclei per cell was 2 in the amphiploid and A. magna, while A. longiglumis showed single micronuclei. Micronuclei can also be formed by chromosomes or their fragments undergoing translocation (Fig. 1h). Nuclei with an irregular shape and showing different level of condensation were observed at a low frequency in A. magna, and more often in A. longiglumis caryopses (Table 1; Fig. 1d, e).

The expected number of chromosomes in endosperm (Table 2) and genomic formulae are as follows: amphiploid 63, CCCDDDAlAlAl; A. magna 42, CCCDDD; and A. longiglumis 21, AlAlAl. The observed disorders, especially the elimination of chromosomes and their fragments as well as the micronuclei formation, gave rise to new sets of chromosomes and the series of chromosome numbers (Table 2). A narrow variation was noted in this characteristic in $A$. magna, whereas in the amphiploid and in A. longiglumis the series of the chromosome numbers exhibited a broad variation. The expected number of chromosomes typical for the $3 n$ endosperm tissue was observed in the amphiploid and both parents. The modal number of chromosomes was distinctly lower and oscillated at $2 n$. The DNA amplification 

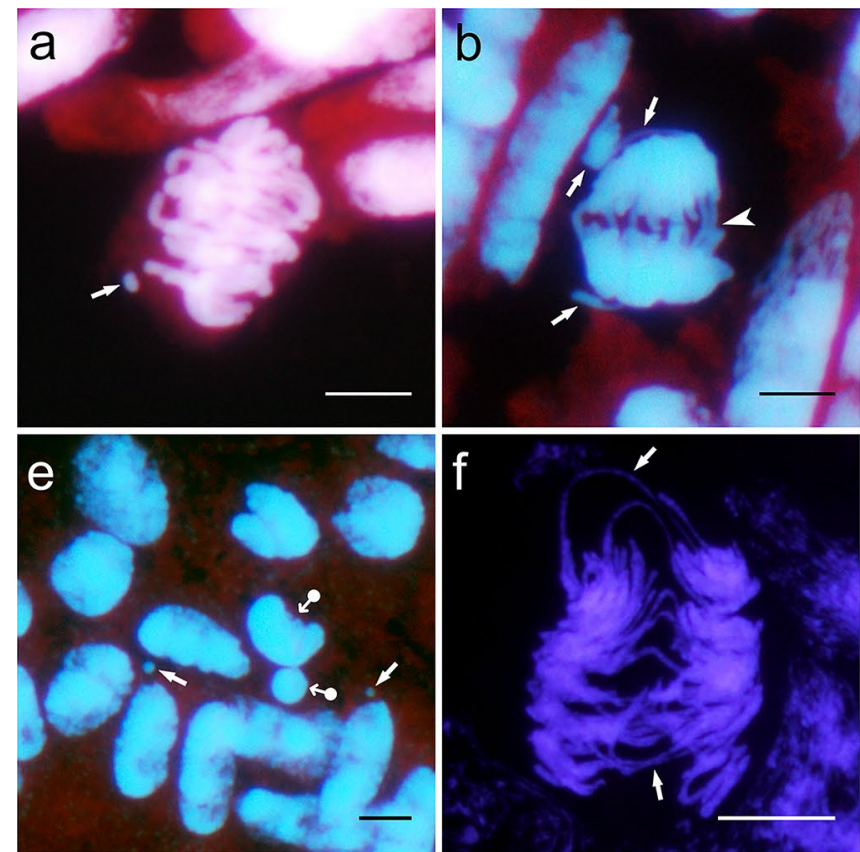

Fig. 1 Examples of cytogenetic disorders in: A. magna (a-c), A. longiglumis (d-f) and $A$. magna $\times$ A. longiglumis amphiploid (g and $\mathbf{h})$. a Metaphase with a fragment of chromosome forming a micronucleus (arrow), b anaphase with multiple (ca. three) bridges (arrowhead) and two precocious chromosome units at the poles (arrows) which are still connected to the poles, $\mathbf{c}$ nucleus with two micronuclei (arrows), $\mathbf{d}$ an irregular nucleus (arrow) before the creation of two nuclei of different sizes, e nuclei with micronuclei (arrows) and a highly condensed

typical of the hyperploidy level occurred in the amphiploid as well as the paternal species.

\section{Translocations in Avena magna}

The two genomic probes obtained from A. nuda (AsAs genomes, green fluorescence) and $A$. eriantha $(\mathrm{CpCp}$ genomes, red fluorescence) were used for the detection of $\mathrm{D}$ and $\mathrm{C}$ genomes in the endosperm nuclei of A. magna (Fig. 2). Six C/D and four D/C translocations were noted in the prophase nucleus ( $2 n=28$, Fig. 2a). C/D marks the transfer of a fragment of the chromosome of the genome $\mathrm{C}$ to the chromosome of the genome $\mathrm{D}$, and $\mathrm{D} / \mathrm{C}$ marks the reverse event. At least one pair $\left(1,1^{\prime}\right)$ were tiny and showed equal reciprocal terminal translocations. The two C/D translocations in the upper right part overlapped partially. The lower one, marked with an arrowhead, ended with the terminal green points of the $\mathrm{D}$ genome. In anaphase, the translocations in the daughter chromosome groups appeared the same $(2 n=28$, Fig. 2c), and four C/D and two D/C translocations were observed. Terminal translocations dominated in the prophase nucleus, however, two intercalary translocations were also observed; and both types were detectable in anaphase (Fig. 2c).The translocations shown in Fig. 2c can be
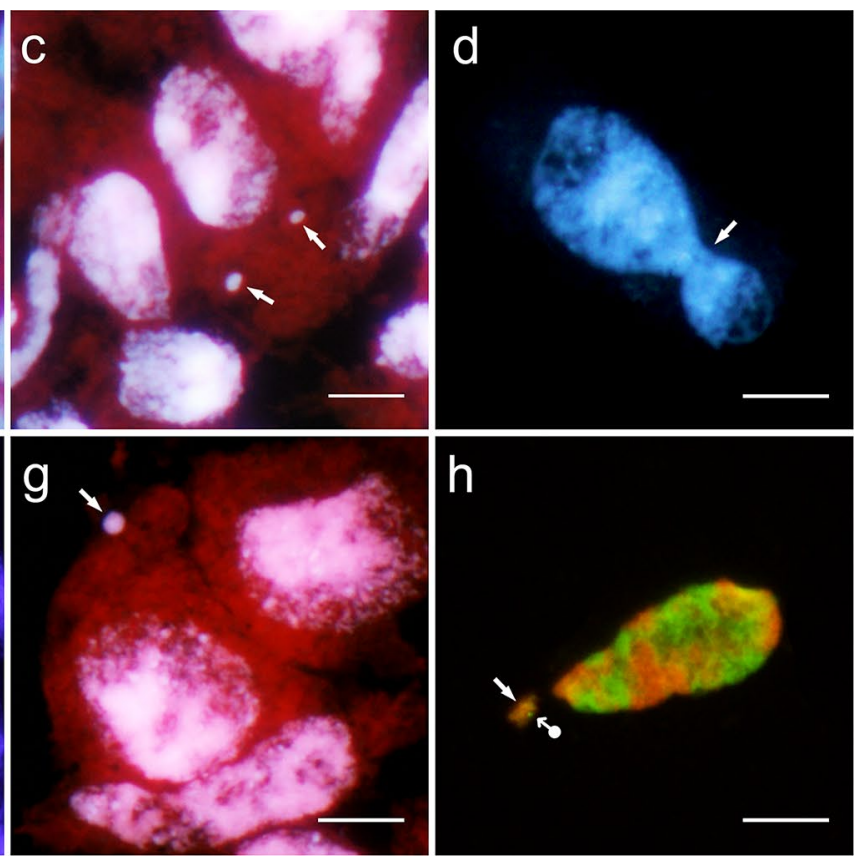

nucleus extruding a micronucleus of the same kind (dot-arrows), $\mathbf{f}$ anaphase with several bridges (arrows), g a micronucleus (arrow) and a group of nuclei at the early prophase, $\mathbf{h}-\mathbf{a}$ micronucleus composed of two genomes, red $\mathrm{C}$ genome (arrow) and green A genome (dotarrow). DAPI fluorescence for $\mathbf{a}-\mathbf{g}$ and counterstained by propidium iodide for $\mathbf{a}, \mathbf{b}, \mathbf{c}, \mathbf{e}, \mathbf{g}$. For $\mathbf{h}$ red fluorescence for $A$. eriantha probe (CpCp genomes) and green fluorescence for $A$. nuda probe (AsAs genomes). Scale bars $10 \mu \mathrm{m}$

better differentiated by observing Fig. S1. In addition to reciprocal translocations (Fig. 2a), single and non-reciprocal translocations were also noted. The differences in the number of both types of translocations proved that the translocation status of the endosperm nuclei in the 'magna' species is variable. Here, one should consider the possible elimination of translocated segments in the micronuclei (Fig. $1 \mathrm{~h}$ for the amphiploid). The DAPI image of the prophase overlapped by the green fluorescence of the DD genomes shown in Fig. $2 b$ indicates that the $\mathrm{CC}$ genomes are not homologous to the probe of genomic DNA from $A$. nuda and that $\mathrm{D}$ genome of A. magna is highly homologous to the As genome from the A. strigosa group (Fig. 2b).

For a sample of nuclei analysed $(n=15)$, the arithmetic average of the $C / D$ translocations was 5.47 per nucleus, while that of the $\mathrm{D} / \mathrm{C}$ translocations was 2.53 . The first type of translocation was less variable (coefficient of variation $\mathrm{V}=16.8 \%$, min-max values 4-6, modal number 6) than the second (coefficient of variation $\mathrm{V}=36.1 \%$, min-max values $2-4$, modal number 2 ). For both types of translocations, the distribution curves were leptokurtic. A bimodal distribution was observed when both curves were overlapped ( $\mathrm{min} \mathrm{D/C}$ and max $\mathrm{C} / \mathrm{D}$ ). Terminal translocations dominated in both $\mathrm{C} / \mathrm{D}$ and $\mathrm{D} / \mathrm{C}$ types; however, in the first type subterminal 


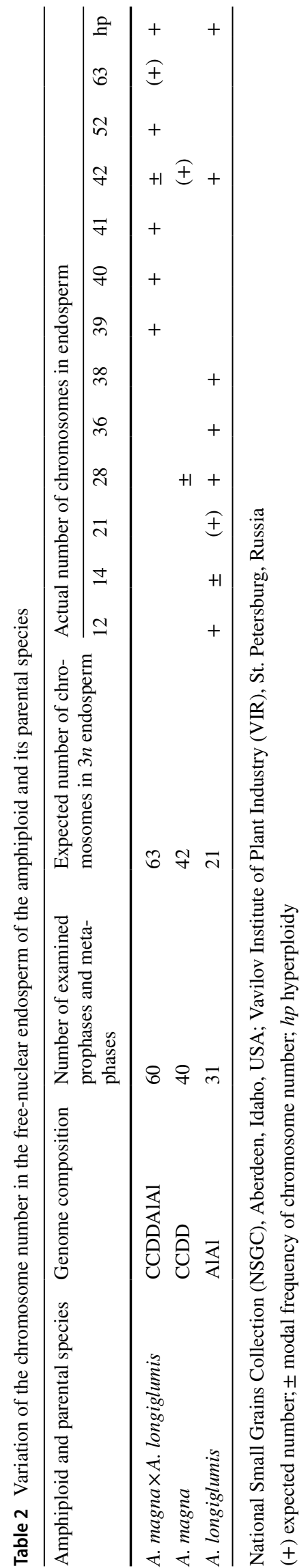

translocations and in the second microtranslocations were also noted.

\section{Translocations in the amphiploid}

The DAPI fluorescence and two genomic probes obtained from $A$. nuda (AsAs genomes, green fluorescence) and $A$. eriantha ( $\mathrm{CpCp}$ genomes, red fluorescence) allowed detecting the $\mathrm{C}, \mathrm{D}$ and $\mathrm{Al}$ genomes and chromosome rearrangements in the endosperm nuclei of the amphiploid. The DAPI staining enabled clear discrimination of individual chromosomes and the level of their chromatin condensation (Fig. 3a). Chromatin condensation was even along the chromosomes a-e and chromosome 3 , but not so in chromosomes 1 and 2, in which the terminal sectors or arms were less condensed. The use of the $\mathrm{Cp}$ probe for genome $\mathrm{C}$ (Fig. 3b) revealed that chromosomes a-e belonged to the $\mathrm{C}$ genome and $\mathrm{b}, \mathrm{c}$ and $\mathrm{d}$ chromosomes showed weaker hybridisation signals on the large terminal sectors. In the presented metaphase, eight terminal and one intercalary $\mathrm{C} / \mathrm{D}$ and $\mathrm{C} / \mathrm{Al}$ translocations were found. There were no reciprocal translocations (Fig. 3b).

Labelling with the As probe of the $\mathrm{D}$ genome resulted in the distinct fluorescence of the $\mathrm{D}$ genome chromosomes in the amphiploid (Fig. 3c). The $\mathrm{C}$ genome chromosomes showed a weak fluorescence. In addition, the chromosomes with an intermediate fluorescence belonging to the $\mathrm{Al}$ genome were identified. This would prove the higher chromosome homeology between the D and Al genomes. The difference between these two genomes in the probe binding was quantitative, and thus, it was difficult to discriminate them. Chromosomes 1-3 belonged to the $\mathrm{D}$ and $\mathrm{D} / \mathrm{Al}$ genomes, of which chromosomes 1 and 2 showed a weaker fluorescence, due to lower chromatin condensation (Fig. 3a). Chromosome 3 had a weaker hybridisation signal on its right arm having the homogenous condensation of chromatin (Fig. 3a). The C/D and C/Al translocations in Fig. 3b were better discriminated after the fluorescence of both probes labelling the $\mathrm{C}$ and $\mathrm{D}$ genomes was overlapped. In addition, a small D/C terminal translocation was detected (Fig. 3d). The dotted lines on chromosomes a-e of the $\mathrm{C}$ genome having the homogenous chromatin condensation (Fig. 3a) indicate large fragments along the chromosome with various level of homology to the probe used. The superposition of the fluorescence of $A$. nuda probe (As genome) on the DAPI fluorescence enabled the discrimination of chromosomes belonging to the $\mathrm{D}, \mathrm{C}$ and $\mathrm{Al}$ genomes in the amphiploid endosperm (Fig. 3e). The dotted lines also indicate a weaker binding of the probe in chromosomes 1 and 2 which correlated with a lower level of chromatin condensation (Fig. 3a) and possible translocation of the entire arm between the $\mathrm{D}$ and $\mathrm{Al}$ genomes in chromosome 3. Differentiation in the level of homology in the $\mathrm{C}$ chromosomes with respect to the 

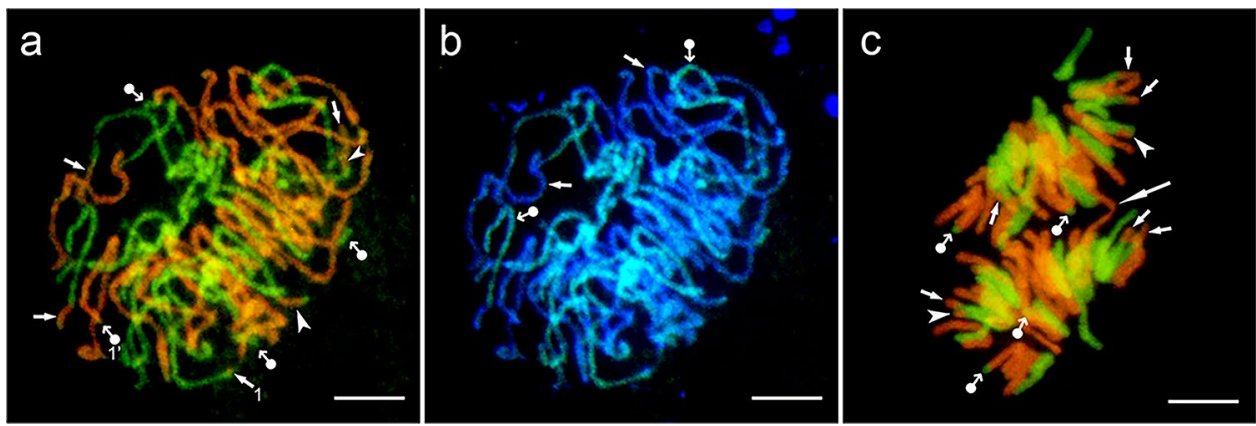

Fig. 2 Chromosome rearrangements in A. magna detected by GISH. a Prophase with four D/C (dot-arrows) and six C/D translocations (arrows for terminal, arrowheads for intercalary), 1 and 1' a pair of terminal reciprocal microtranslocations; $\mathbf{b}$ green chromosomes of the D genome marked with the A. nuda probe (dot-arrows) and DAPI

Cp genome probe is shown in Fig. 3f with combined DAPI fluorescence and fluorescence of both probes (chromosomes $\mathrm{a}, \mathrm{b}, \mathrm{c}, \mathrm{d}, \mathrm{e})$. Large, continuous fragments of chromosomes with a weaker probe binding may also demonstrate intragenomic rearrangements.

For a sample of nuclei analysed, the arithmetic average of the $\mathrm{C} / \mathrm{D}$ translocations was 4.14 per nucleus, while that of the $\mathrm{D} / \mathrm{C}$ translocations was 1.86 . The first type of translocation was less variable (coefficient of variation $\mathrm{V}=57 \%$, min-max values $0-8$ ) than the second type (coefficient of variation $\mathrm{V}=70 \%$, min-max values $0-4$ ). The total number of translocations ranged from 0 to 11 . For a small sample $(n=13)$, the distribution curve was platykurtic for the C/D translocations with modal numbers $2,3,4,6$ and 7 , while it was leptokurtic for the $\mathrm{D} / \mathrm{C}$ translocations with modal number 2 . The variation of translocations was distinctly larger in the amphiploid compared to the maternal species.

\section{Spatial arrangement of genomes}

At the interphase and various stages of mitosis, the chromatin and chromosomes were not distributed randomly. A prophase nucleus in A. magna showed a sectorial-concentric domain arrangement of the $\mathrm{D}$ and $\mathrm{C}$ chromosomes (Fig. 4a). Terminal and intercalary translocations were located at the periphery. In the amphiploid, the central part of a nucleus (marked by a dot-arrow in Fig. 4b) was found to be more condensed than its periphery (marked by arrows) and related to the green $\mathrm{D}$ genome. The outer part showing a weak green fluorescence indicated the location of the $\mathrm{Al}$ genome; however, another interpretation is also possible; the outerpart might indicate decondensed chromatin of the $\mathrm{D}$ and $\mathrm{Al}$ genomes. The red $\mathrm{C}$ genomes were organised in the form of bands while in the outer part of the nucleus they were condensed (marked by white dots). In addition, a small dot of the $\mathrm{C}$ genome (small arrow) was seen in an area of blue chromosomes of the $\mathrm{C}$ genome (arrows), c anaphase translocations (small arrows) and a bridge (large arrow); in both groups of chromosomes, the same number of translocations is marked by arrows for terminal $\mathrm{C} / \mathrm{D}$, arrowheads for subterminal $\mathrm{C} / \mathrm{D}$ and dotarrows for D/C. Scale bars $10 \mu \mathrm{m}$

the $\mathrm{Al}$ or $\mathrm{D}+\mathrm{Al}$ genomes. This fluorescence signal can be interpreted as a chromosome microrearrangement. Probably, such a small change on metaphase chromosomes cannot be detected. The green $\mathrm{D}$ and $\mathrm{Al}$ genomes (indicated by letter a in Fig. 4c) versus the red $\mathrm{C}$ genomes (letter b) appeared to be situated side-by-side. The composite fluorescence red, green and blue (Fig. 4d) revealed a new arrangement of genomes. The red $\mathrm{Cp}$ and green $\mathrm{D}$ genomes dominated the outside area of the prophase nucleus (dots and arrows in Fig. 4d), while the blue Al genomes also having a weak green fluorescence were situated mainly inside and only tiny parts of $\mathrm{Al}$ chromosomes were located outside of the prophase nucleus (asterisks in Fig. 4d). The arrangement of chromosomes in Fig. $4 \mathrm{~d}$ can be described as a sectorial-concentric pattern, which is similar to that observed in A. magna.

\section{Discussion}

\section{Cytogenetic disorders}

Combining the genomes of different species, for instance wheat and rye, leads to occurrence of chromatid or chromosomal bridges in the hybrid mitotic cycle, and the BFB cycle (Lukaszewski 1995). The BFB cycle was also noted in the cells of maize callus culture. It appeared at heterochromatic knobs, and the broken ends were later healed by telomere sequences (Santos-Serejo and Aguiar-Perecin 2016). In barley and maize, Kilian et al. (1998) noted a decrease in telomerase activity during endosperm development as well as telomere shortening. In human cancer cells, telomere loss activates the BFB cycle and consequently leads to many chromosomal rearrangements, including microtranslocations and deletions (Lo et al. 2002). Such events are supported by data on telomerase inactivity in Arabidopsis, which was shown to increase fusion and breakage 

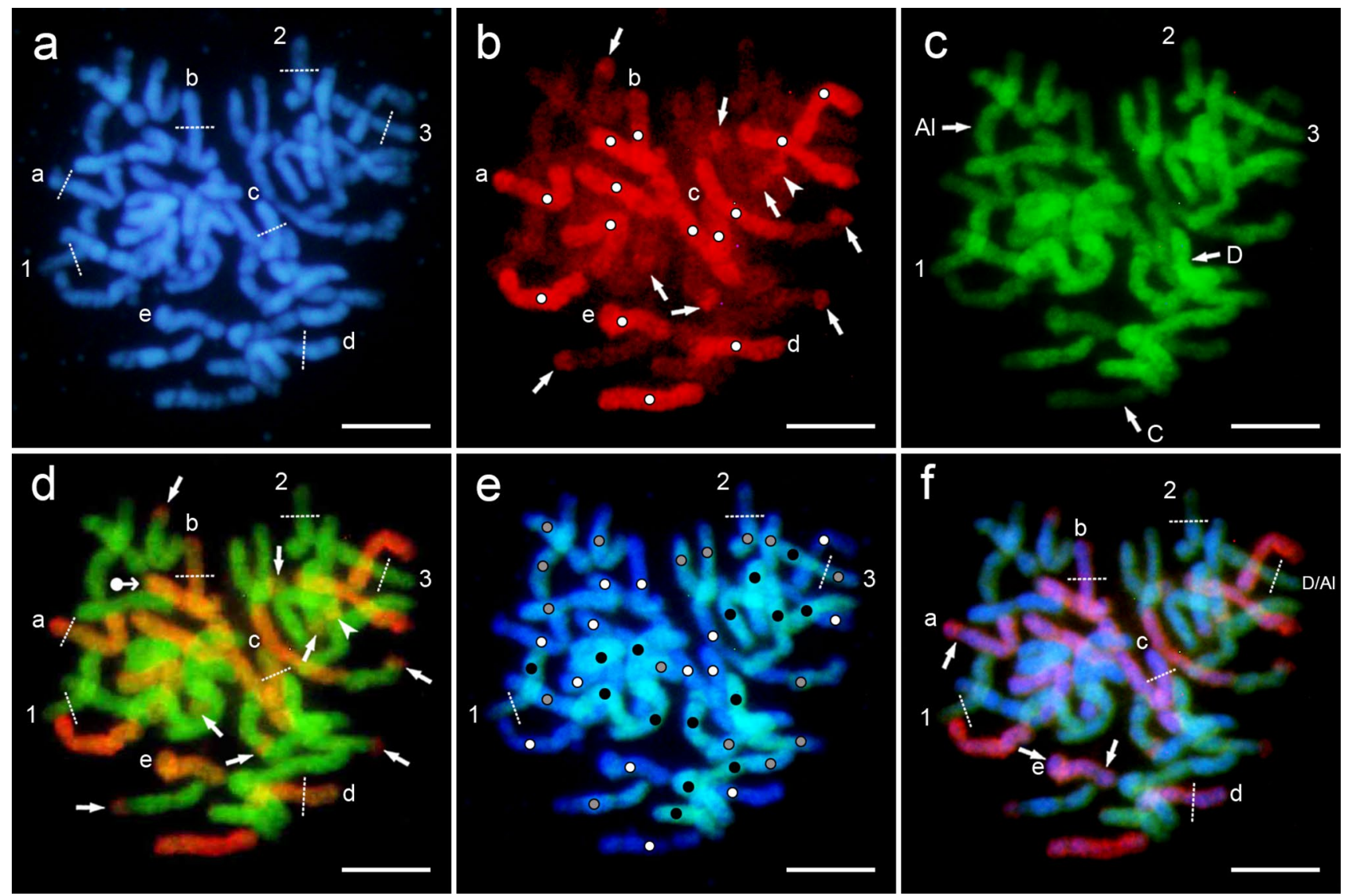

Fig. 3 Detection of genomes and translocations in the $\mathrm{Am} \times \mathrm{Al}$ freenuclear endosperm. Two probes of the total genomic DNA were used-Cp genome from $A$. eriantha (red) and As genome from $A$. nuda (green); in addition, the slides were counterstained by DAPI (blue). a A metaphase $(3 n=42)$ showing DAPI fluorescence, with different sectors in chromosomes separated by dotted lines, numbers and letters; ( 1 and 2 mark the sectors of lower DNA condensation, and for others, designation of sectors with reduced homology to the probes used (see b-f); b red fluorescence of eight terminal (arrows) and one intercalary (arrowhead) $\mathrm{C} / \mathrm{D}, \mathrm{Al}$ translocations marked by using the $A$. eriantha probe, with white dots indicating the $\mathrm{C}$ genome chromosomes; c green fluorescence shows the homology of three genomes $(\mathrm{C}, \mathrm{D}, \mathrm{Al})$ of the amphiploid after hybridisation of the $A$. nuda probe; $\mathbf{d}$ red and green fluorescence of two overlapped probes

of chromosomes at anaphase-telophase and subsequently leads to unequal distribution of chromatin and rDNA to sister nuclei (Siroky et al. 2003). This cytogenetic behaviour was multiplied during repeated BFB cycles.

In a syncytial endosperm of $\mathrm{Am} \times \mathrm{Al}$, no bridges were noted, but were observed in its root tissues (Świetlikowska 2008). In the Triticale endosperm, Kaltsikes et al. (1975) observed a low proportion of bridges and attributed such a frequency to the shorter anaphase-telophase stage. In the other amphiploids of oats, bridges were formed together with rings and telocentrics (Tomaszewska and Kosina 2018). These events were evidently components of the BFB cycle occurring in the free-nuclear stadium of the changing oat marks the same translocations as in $\mathbf{b}$, and in addition one tiny terminal D/C translocation (dot-arrow); for chromosomes ' $a$ ' to ' $e$ ', the sectors of lowered homology to the $\mathrm{C}$ genome probe or even arm translocations (see 'c' chromosome) are shown; e the metaphase marked by DAPI and green fluorescence of the A. eriantha probe three genomes can be identified: white dots for C, black for D and grey for Al genome; for chromosomes ' 1 ' and' 2 ' arms of lower DNA condensation and for chromosome ' 3 ' the possible D/Al arm translocation (also shown in $\mathbf{f}$ ) are distinguished; $\mathbf{f}$ the metaphase with the DAPI fluorescence and fluorescence of both probes overlapped (for chromosomes ' $a$ ' and, ' $e$ ' intercalary and for chromosomes ' $b$, 'c' and ' $d$ ' large terminal lowering of homology to the Cp probe or chromosome rearrangements are well visible). Scale bars $10 \mu \mathrm{m}$

embryo sac. In a group of oat amphiploids and their parental species, the frequency of bridges was determined at a similar level, but the sum of various cytogenetic anomalies was found to be comparatively much higher in amphiploids. (Tomaszewska and Kosina 2018).

Elimination of chromosomes and their fragments and micronuclei formation are two events which are important for the subsequent development of endosperm tissue. In $A$. sativa varieties, elimination of micronuclei from microspores in the form of microcytes was observed, which lowered the male fertility (Baptista-Giacomelli et al. 2000). Other data showed that pearl millet-origin micronuclei of the wheat $\times$ pearl millet hybrid embryos were extruded from 
Fig. 4 Spatial arrangement of genomes in A. magna (a) and the amphiploid (b-d). a A prophase sectorial-concentric distribution of the D (lines) and C (dashed lines) genome chromosomes, with terminal (arrows) and intercalary (arrowhead) translocations found outside; $\mathbf{b}$ an interphase-prophase nucleus with a condensed centre (dotarrow), decondensedexternal parts (arrows), the $\mathrm{C}$ genome condensed at the periphery of the nucleus (white dots) and an orange dot showing the D/C chromosome microrearrangement (small arrow with dashed line); c a side-by-side arrangement of the green $\mathrm{D}, \mathrm{Al}$ genome (a) and red $\mathrm{C}$ genome (b) in the nucleus of an early prophase; $\mathbf{d}$ a sectorial-concentric arrangement of genomes in the nucleus of prophase (green D genome (arrows), red C genome (white dots) and blue $\mathrm{Al}$ genome (asterisks)). Scale bars $10 \mu \mathrm{m}$
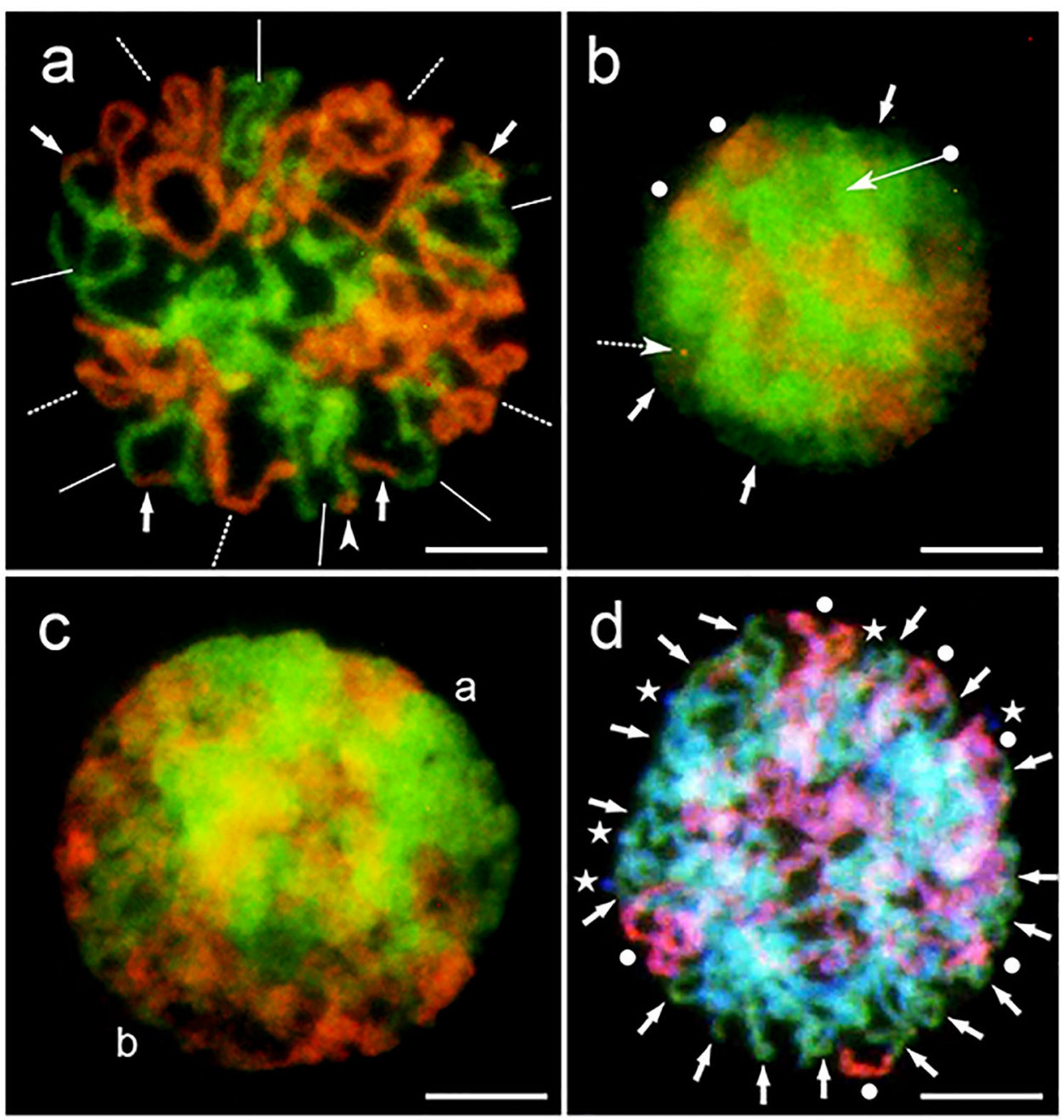

the interphase nuclei in the form of highly heterochromatinised bodies, and were finally fragmented (Gernand et al. 2005). Highly condensed irregular nuclei of various sizes showed characteristics of apoptosis. Such type of nuclear degeneration during programmed cell death has been noted for antipodals in wheat (An and You 2004). It is highly probable that the high frequency of micronuclei in $\mathrm{Am} \times \mathrm{Al}$ and its parents is responsible for the selective elimination of anomalous structures with DNA and reduction in the level of syncytial ploidy.

A consequence of cytogenetic anomalies in the endosperm is the formation of dysfunctional nuclei and their elimination during apoptosis. Kaltsikes et al. (1975) suggested that in Triticale, irregular endosperm nuclei having different sizes and amounts of DNA were formed after breaks of bridges. In addition, many nuclei were noted to be necrotic (apoptotic?), and undoubtedly were selectively eliminated. Such a selection has also been reported in an oat amphiploid, Avena barbata Pott ex Link $\times$ A. sativa (Kosina and Tomaszewska 2011), as well as in some oat species (Tomaszewska and Kosina 2018). The apoptotic selection of nuclei can decrease the level of endosperm ploidy and maintain a lower modal number of chromosomes than that expected for a triploid tissue. This phenomenon not only occurs in polyploid forms but has also been observed in a diploid species (e.g. A. longiglumis, Table 2) and is probably necessary to stabilise development of the storage tissue. However, A. longiglumis displayed a broad range of chromosome numbers, from 12 to highly polyploid nuclei. In addition, the species showed a low frequency of bridges and micronuclei, and no chromosome elimination. These data demonstrate that the syncytial endosperm of $A$. longiglumis is cytogenetically more stable than that of other taxa and its nuclei undergo less apoptotic segregation. Such cytogenetic behavior leads to increased variation in the number of chromosomes and the level of ploidy.

\section{Translocations}

The observed translocations occurred between all oat genomes in the amphiploid nuclear endosperm. These chromosomal events were predominantly terminal and were 
of various sizes. In the endosperm, translocations can be accompanied by other structural rearrangements, including the BFB cycle. In addition, somatic (mitotic) crossing over (SCO) may rarely occur in the endosperm tissue at each developmental stage (Tomaszewska and Kosina 2018). SCO could be observed as a mosaic of GISH signals (+or - ) across the chromosome, and this uncommon event cannot be neglected in the endosperm.

A dotted pattern of probe fluorescence, especially red versus blue, is shown in Fig. 3f. Such a pattern is interpreted as weak hybridisation of the genomic DNA probe at a low-homologous target (Schwarzacher and Heslop-Harrison 2000). This sequence-homology-dependent strength of fluorescence has been well exemplified by Seijo et al. (2007) in their study, in which the genomic DNAs obtained from several wild species of peanut were applied as probes to detect the chromosomes of Arachis hypogaea L. The fluorescence of dotted scattered signals was observed to differ with their intensity and number depending on the homology of the probe to the genome of A. hypogaea. In the amphiploid, weak hybridisation signals can be located at the parts of chromosome showing less condensed chromatin. Such parts were visible as large terminals (Fig. 3a, DAPI fluorescence, chromosomes 1 and 2). Thus, in the oat amphiploid, the segments of chromosomes with no visible fluorescence signals of a given genomic DNA probe can be considered as fragments having a reduced homology to the applied probe. These segments do not have sharp limits due to the dotted hybridisation at the contact with parts having uniform fluorescence.

The heterochromatic regions of chromosomes have been recognised as more fragile than the euchromatic sites (Jannsen et al. 2018). In the case of A. sativa, most chromosomal exchanges occur in the heterochromatic $\mathrm{C}$ genome (Chen and Armstrong 1994; Jellen et al. 1994). Such a tendency to create breaks and chromosome fragments was also exemplified for the $\mathrm{C}$ genome of Avena fatua $\mathrm{L}$. and other oat hexaploids by Yang et al. (1999). Fluminhan and Kameya (1997) discovered that breaks were associated with heterochromatic knobs in maize chromosomes. C-banding and in situ DNA hybridisation are two useful techniques for studying the interrelations between translocations and heterochromatin. The compatibility of heterochromatic C-bands with the heterochromatin repetitive sequences at the in situ hybridisation site has been demonstrated for some plants, including Allium fistulosum L. (Irifune et al. 1995) and Alstroemeria L. (Kuipers et al. 1997). Thus, the frequency of translocations in the oat endosperm must be related to the differences in the amount of heterochromatin between the genomes. In the amphiploid and its maternal species, the dominance of the C/D-type translocation is distinct at terminal positions. The dominance of terminal translocations in the oat chromosomes is corroborated by the diversity of repeat sequences localised in them (Liu et al. 2019). Compared to other oat tissues, the dose of heterochromatin is increased in endosperm due to its input in the CCC maternal genomes. Such a relation was also proved for the endosperm of Arabidopsis (Baroux et al. 2007). Thus, a positive correlation between the dose of heterochromatin and the C/D translocation number in the endosperm of the amphiploid can be expected. The comparative numbers of translocations in root mitoses have not been studied for the amphiploid.

Using a probe of $A$. eriantha (Cp genome), Nikoloudakis and Katsiotis (2015) determined four major C/A (marked $\mathrm{CD}$ in this paper) terminal translocations in the root tissue of a triploid hybrid A. magna $\times$ A. longiglumis. In A. magna, the number of such translocations was determined as six by using oligo-probes (Fominaya et al. 1995; Luo et al. 2018b) and as eight by using genomic DNA (Leggett et al. 1994) or oligo-Am1 probe (Luo et al. 2018a). The translocations were tiny and terminal or sub-terminal. Leggett et al. (1994) concluded in their study that non-reciprocal C/A (marked C/D in this paper) translocations dominated. These data prove that the translocations occurred exclusively between the $\mathrm{C}$ and $\mathrm{D}$ genomes belonging to A. magna, while the chromosomes of A. longiglumis did not participate in these exchanges in the triploid hybrid. However, the amphiploid endosperm differs in this respect. Figure $3 e$ confirms the occurrence of $\mathrm{C} / \mathrm{D}$ and $\mathrm{C} / \mathrm{Al}$ translocations. The first ones are older and also noted in A. magna, whereas the second ones are new and occurred during the hybridisation process. Furthermore, the $\mathrm{D} / \mathrm{Al}$ translocation should be treated as a rare and new event (Fig. 3f).

In an A. strigosa $\times A$. maroccana amphiploid $(2 n=42)$, eight C/A (marked C/D in this paper) translocations (six terminal and two intercalary) and two tiny terminal A/C (marked D/C in this paper) translocations were observed in the root tissue (Ueno and Morikawa 2007). These results are very similar to those reported in this study on young nuclear endosperm (Fig. 3); however, the number of translocations can increase with the chromosome number (Table 2). According to Hayasaki et al. (2000), the number of translocations in oats is positively correlated with the level of ploidy.

The above amphiploids differ from each other in the following: the introduced genomes ( $\mathrm{As}$ or $\mathrm{Al}$ ); the parental status of species (maternal or paternal), and the cytogenetic stability of the tested tissues (root or endosperm). Despite these differences, the high similarity of the results proves the dominant role of the $\mathrm{C}$ genome in the translocations occurring in both tissue types-root and endosperm. The data show that the $\mathrm{C} / \mathrm{D}$ and $\mathrm{D} / \mathrm{C}$ translocations vary by number in the same nucleus, and are therefore non-reciprocal. A question arises whether this is a natural state or whether the reciprocal translocations are eliminated. Schubert and Lysak (2011) postulated that non-reciprocal translocations are, in 
fact, a result of unbalanced chromosome segregation. In the syncytial endosperm, the selection of dysfunctional nuclei and micronuclei (Fig. 1e), as a product of such segregation, occurs, and the translocated chromosomes or their fragments (Fig. 1h) can be removed, following which the level of ploidy decreases (Table 2). However, the unequal number of $\mathrm{C} / \mathrm{D}$ versus $\mathrm{D} / \mathrm{C}$ translocations in the $A$. magna anaphase is maintained in the sister nuclei (Fig. 2c), which does not support the conclusion about the unbalanced segregation origin of non-reciprocal translocations. The same ratio of both translocations observed in root tissue (Hayasaki et al. 2000; Leggett et al. 1994; Nikoloudakis and Katsiotis 2015; Ueno and Morikawa 2007) proves that such translocations are oat-specific and truly non-reciprocal. The present study shows that reciprocal translocations are not frequent.

Recent studies have indicated a special role for A. longiglumis in the evolution of oat tetra- and hexaploids. The $\mathrm{Al}$ genome present in the amphiploid is considered ancestral to the other A genomes (Drossou et al. 2004; Holden 1966). As previously mentioned, $\mathrm{Fu}$ (2018) attributed a key role to $A$. longiglumis in the hybrid evolution of oats with the AACC (=CCDD) and AACCDD genomes. During this evolution, A. longiglumis was a maternal as well as a paternal component when mating with $A$. insularis.

When crossed with A. maroccana, A. longiglumis (AlAl genomes) showed a higher level of meiotic chromosome homology compared to A. strigosa (AsAs genomes) (Rajhathy 1991). In this species, the accession $\mathrm{Cw}$ 57, which was used to create the amphiploid $(\mathrm{Am} \times \mathrm{Al}$ is a young breeding form, created in the early 1980s; Ref.: https://triti ceaetollbox.org/POOL/EntryShow.php?GID=5330\&NGen= 3\&METHOD=ancestry), increases the homeologous pairing in hybrids (Rajhathy and Thomas 1972; Thomas and AlAnsari 1980). According to Jellen and Leggett (2006), the A-genome of A. maroccana differs from that of the diploid species, and so the genomic formula of this species should be rather CCDD, and not AACC. This was also supported by Yan et al. (2016). The last data obtained by using the probes oligo-Am 1 and oligo-(TTC) ${ }_{5}$ in the FISH analysis showed that chromosomes of the AA genomes of A. magna should be renamed as belonging to the DD genomes (Yan et al. 2021).

The present paper shows that the hybridisation signal obtained for the A. nuda probe (AsAs group of diploids) is clear and uniform along DD chromosomes in both A. magna and $\mathrm{Am} \times \mathrm{Al}$, while it is weaker in $\mathrm{Am} \times \mathrm{Al}$ for the 'longiglumis'-chromosomes. Such data seem to be contradictory to those cited by Jellen and Leggett (2006). However, assuming that the $\mathrm{A}$ and $\mathrm{D}$ genomes are evolutionarily younger than the $\mathrm{Al}$ genome, the strong hybridisation signal between the A. nuda probe and the amphiploid DD genomes, and weaker signal observed for the $\mathrm{Al}$ genome, can prove the similarity between A and D genomes as shown by Linares et al. (1998).
The fluorescence in situ hybridization analyses of the root mitoses which were recently carried out in A. magna and Avena murphyi Ladiz. using specific probes for the $\mathrm{C}$ and $\mathrm{D}$ genomes confirms the genome composition CCDD in tetraploids previously designated as AACC (Paulina Tomaszewska, pers. comm.). Considering the role played by A. longiglumis in the evolution of CCDD and AACCDD oats and its phylogenetic closeness to them (Chew et al. 2016; Fu 2018; Yan et al. 2016), the genomic formula of the amphiploid can be accepted as CCDDAlAl and that of its endosperm as CCCDDDAlAlAl.

The old, large translocations were introduced by $A$. magna, while the new ones may have arisen between the 'magna' CCDD genomes and the new $\mathrm{Al}$ genome. The D/ $\mathrm{Al}$ translocation should considered as new (Fig. 3f). As a rule, meiosis in parental species having old translocations is regular, but with defects in hybrids and amphiploids (Holden 1966; Ladizinsky 1998; Leggett 1998; Rajhathy 1971), which can be attributed to the occurrence of new translocations and other chromosomal rearrangements. These cytogenetic events can be more frequently observed in the endosperm than in root meristems; however, the selection of dysfunctional nuclei decreases the number of chromosomes and their rearrangements that could be observed in the endosperm (Table 2; Tomaszewska 2017). This type of selection is commonly made through the apoptosis process (Tomaszewska and Kosina 2018).

\section{Spatial arrangement of genomes}

The non-random distribution of chromosomes in the metaphases was documented in an earlier study by Müller (1909) in the root cells of Yucca L. This observation was later supplemented by the findings reported for other Monocotyledonae species by Darlington (1956). Two types of chromosomes, tiny and large, which were separately scattered, were identified. This phenomenon was clearly seen in hybrids in which two different sets of chromosomes of parental origin formed a nucleus. In common, chromosomes are arranged either side-by-side or concentrically (Bennett 1984). Chromosome separation can be identified by the difference in dimensions, as well as in C-banding, as reported for the hybrid Hordeum L. $\times$ Psathyrostachys Nevski ex Roshev. (Linde-Laursen and Jensen 1991). In barley, shorter and more heterochromatic C-banding chromosomes were found in the centre during metaphase, while in the case of Psathyrostachys, longer chromosomes were observed concentrically outside. The concentric pattern can often be realised as a sectorial arrangement in which the size of the sectors corresponds exactly to the number of chromosomes or the amount of DNA in the separated genomes (Kosina 1999; Kosina and Heslop-Harrison 1996). Leitch et al. (1991) proved that the spatial separation of chromatin, and then 
chromosomes, from the genomes of different origins persists throughout the cell cycle.

In this study, the sectorial-concentric arrangement of chromatin is exemplified for A. magna and $\mathrm{Am} \times \mathrm{Al}$ (Fig. 4). At interphase, a side-by-side pattern was also noted. The outer parts of the interphase nucleus showed a weaker green fluorescence of chromatin which can be interpreted as $\mathrm{Al}$ genome. In this position, it is possible to locate nucleoli non-hybridising with the DNA of a probe and showing a weak fluorescence. However, Heslop-Harrison et al (1993) proved that the nucleoli in somatic interphase nuclei were located in the centre of the nucleus, and so the weak fluorescence of peripheral chromatin can indicate some decondensation of the $\mathrm{Al}$ chromatin. This conclusion is confirmed by the location of $25 \mathrm{~S}$ rDNA loci which was not outside but in the centre of the nuclei in the oat amphiploid (Tomaszewska 2017). The pattern of genome arrangement is sectorial-concentric in the prophase nuclei, but in interphase it is different. Gleba et al. (1987) proved that in old somatic distant hybrids the genome arrangement changed from segmental to sectorial. In the oat endosperm, nuclei approaching apoptosis showed concentric arrangement of genomes (Tomaszewska and Kosina 2013). It seems probable that in developmentally unstable hybrid tissues, such as endosperm or cell cultures, the pattern of genome arrangement can be variable.

\section{Concluding remarks}

Among the cytogenetic disorders, appearance of bridges and elimination of chromatin in the final form of micronuclei, including translocated segments, are considered important for the functioning of the future endosperm tissue. A series of disorders can be associated with the BFB cycle. A decrease of freenuclear endosperm ploidy from the level of $3 n$ and higher proves that many polyploid nuclei are eliminated during apoptosis. The modal number of chromosomes is close to $2 n$ and seems to be optimal for endosperm development in both parental forms and amphiploid. Structural specificity of the subtelomeric regions of A. magna chromosomes which are in the form of heterochromatin blocks facilitates the translocation of its $\mathrm{C}$ genome fragments into other oat genomes. The maternal species of the $\mathrm{Am} \times \mathrm{Al}$ amphiploid has its own large $\mathrm{C} / \mathrm{D}$ translocations, and in the free-nuclear endosperm, these translocations occur similarly as in root tissues, compared with the reference data. Such events relate to the nuclei in both tissues with the same or similar level of ploidy.

C/D translocations occurred more commonly than D/C translocations and usually in the terminal parts of chromosomes, while subterminal or intercalary translocations occurred less often. Such status seems to be conservative. Generally, translocations were single and non-reciprocal, or rarely reciprocal. The occurrence of $\mathrm{D} / \mathrm{C}$ translocations was more variable than the C/D type. Small or even microrearrangements of chromosomes were also observed in the amphiploid. Large fragments in the $\mathrm{C}$ chromosomes that showed poor homology to the used probe may prove that the $\mathrm{C}$ genome underwent intragenomic rearrangements, which seems possible with its heterochromatin status. During the microevolution of the amphiploid, new rearrangements took place invoving the $\mathrm{Al}$ genome, which were noted as a broader variation of the number of translocations than in $A$. magna. The last reference data prove that $A$. longiglumis is a possible progenitor of CCDD (previously AACC) and AAC$\mathrm{CDD}$ oats. Both $\mathrm{D}=(\mathrm{As})$ and $\mathrm{Al}$ genomes studied in the present paper showed a high homeology, so it is proposed that the genomic designations of AACC tetraploids should be changed into CCDD or CCDIDl (Dl - the A. longiglumis genome changed during the evolution of the CCDD tertraploids). Such an approach needs more research focused on the level of homeology/homology between the D genome in the CCDD oat tetraploids and the variants of the Al genome.

It has also been proved that the parental genomes of the $\mathrm{Am} \times \mathrm{Al}$ amphiploid are not mixed together but remain spatially separated and arranged in a sectorial-concentric pattern. Furthermore, a side-by-side pattern was observed for this taxon, especially in the early prophase. Thus, the pattern of the spatial genome arrangement appears to be variable, particularly in less stable tissues such as the endosperm of hybrids or plant tissue cultures.

Supplementary Information The online version contains supplementary material available at https://doi.org/10.1007/s10265-021-01314-3.

Acknowledgements The authors would like to thank the following institutions for providing seed samples of oat amphiploid and species: National Small Grains Collection (Aberdeen, Idaho, USA) and Vavilov Institute of Plant Industry (St. Petersburg, Russia). This research was financially supported by the statutory fund of the Institute of Experimental Biology, University of Wroclaw, Poland. This report is a part of the $\mathrm{PhD}$ thesis written by P. Tomaszewska at the University of Wroclaw, Poland.

Author contributions PT designed and conducted all cytogenetic analyses and interpreted the results. PT and RK prepared figures and wrote the article. RK provided research idea, supervised the experiments and research documentation. The authors read and approved the manuscript.

Funding Statutory funds (1232/M/IBR/11) for PT supported by University of Wrocław.

Availability of data and material Raw cytogenetic pictures stored electronically.

Code availability Not applicable.

\section{Declarations}

Conflict of interest The authors declare that they have no conflict of interest. 
Ethical approval The authors guarantee compliance with ethical standards.

Open Access This article is licensed under a Creative Commons Attribution 4.0 International License, which permits use, sharing, adaptation, distribution and reproduction in any medium or format, as long as you give appropriate credit to the original author(s) and the source, provide a link to the Creative Commons licence, and indicate if changes were made. The images or other third party material in this article are included in the article's Creative Commons licence, unless indicated otherwise in a credit line to the material. If material is not included in the article's Creative Commons licence and your intended use is not permitted by statutory regulation or exceeds the permitted use, you will need to obtain permission directly from the copyright holder. To view a copy of this licence, visit http://creativecommons.org/licenses/by/4.0/.

\section{References}

An LH, You RL (2004) Studies on nuclear degeneration during programmed cell death of synergid and antipodal cells in Triticum aestivum. Sex Plant Reprod 17:195-201. https://doi.org/10.1007/ s00497-004-0220-1

Badaeva ED, Loskutov IG, Shelukhina OY, Pukhalsky VA (2005) Cytogenetic analysis of diploid Avena L. species containing the As genome. Russ J Genet 41:1428-1433

Baptista-Giacomelli FR, Pagliarini MS, de Almeida JL (2000) Elimination of micronuclei from microspores in a Brazilian oat (Avena sativa $\mathrm{L}$.) variety. Genet Mol Biol. https://doi.org/10.1590/S141547572000000300029

Baroux C, Pecinka A, Fuchs J, Schubert I, Grossniklaus U (2007) The triploid endosperm genome of Arabidopsis adopts a peculiar, parental-dosage-dependent chromatin organization. Plant Cell 19:1782-1794

Bennett MD (1984) Nuclear architecture and its manipulation. In: Gustafson JP (ed) Gene manipulation in plant improvement, Stadler genetics symposia series. Springer, Boston, pp 469-502

Chen Q, Armstrong K (1994) Genomic in situ hybridization in Avena sativa. Genome 37:607-612

Chew P, Meade K, Hayes A, Harjes C, Bao Y, Beattie AD, PuddephatGusminiTanksley IGSD (2016) A study on the genetic relationships of Avena taxa and the origins of hexaploid oat. Theor Appl Genet 129:1405-1415. https://doi.org/10.1007/ s00122-016-2712-4

Darlington CD (1956) Chromosome botany. George Allen and Unwin Ltd., London

Doyle JJ, Doyle JL (1990) A rapid total DNA preparation procedure for fresh plant tissue. Focus 12:13-15

Drossou A, Katsiotis A, Leggett JM, Loukas M, Tsakas S (2004) Genome and species relationships in genus Avena based on RAPD and AFLP molecular markers. Theor Appl Genet 109:48-54

Endo TR, Gill BS (1984) The heterochromatin distribution and genome evolution in diploid species of Elymus and Agropyron. Can J Genet Cytol 26:669-678

Fluminhan A, Kameya T (1997) Involvement of knob heterochromatin in mitotic abnormalities in germinating aged seeds of maize. Genome 40:91-98

Fominaya A, Vega C, Ferrer E (1988a) Giemsa C-banded karyotypes of Avena species. Genome 30:627-632

Fominaya A, Vega C, Ferrer E (1988b) C-banding and nucleolar activity of tetraploid Avena species. Genome 30:633-638

Fominaya A, Hueros G, Loarce Y, Ferrer E (1995) Chromosomal distribution of a repeated DNA sequence from C-genome heterochromatin and the identification of a new ribosomal DNA locus in the Avena genus. Genome 38:548-557

Fominaya A, Loarce Y, Montes A, Ferrer E (2017) Chromosomal distribution patterns of the (AC) 10 microsatellite and other repetitive sequences, and their use in chromosome rearrangement analysis of Avena species. Genome 60:216-227

$\mathrm{Fu}$ Y-B (2018) Oat evolution revealed in the maternal lineages of 25 Avena species. Sci Rep 8:4252. https://doi.org/10.1038/ s41598-018-22478-4

Gernand D, Rutten T, Varshney A, Rubtsova M, Prodanovic S, Brüß C, Kumlehn J, Matzk F, Houben A (2005) Uniparental chromosome elimination at mitosis and interphase in wheat and pearl millet crosses involves micronucleus formation, progressive heterochromatinization, and DNA fragmentation. Plant Cell 17:2431-2438

Gleba YY, Parokonny A, Kotov V, Negrutiu I, Momot V (1987) Spatial separation of parental genomes in hybrids of somatic plant cell. Proc Natl Acad Sci USA 84:3709-3713

Grant V (1981) Plant speciation. Columbia University Press, New York

Hayasaki M, Morikawa T, Tarumoto I (2000) Intergenomic translocations of polyploid oats (genus Avena) revealed by genomic in situ hybridization. Genes Genet Syst 75:167-171

Heneen W (1963) Extensive chromosome breakage occurring spontaneously in a certain individual of Elymus farctus (=Agropyron junceum). Hereditas 49:1-32

Heslop-Harrison JS (1990) Gene expression and parental dominance in hybrid plants. Development Suppl.:21-28

Heslop-Harrison JS, Leitch AR, Schwarzacher T (1993) The physical organization of interphase nuclei. In: Heslop-Harrison JS, Flavell RB (eds) The chromosome. Bios, Oxford, pp 221-232

Holden JHW (1966) Species relationships in the Avenae. Chromosoma 20:75-124

https://triticeaetoolbox.org/POOL/EntryShow.php?GID=5330\& $\mathrm{NGen}=3 \& \mathrm{METHOD}=$ ancestry

Irifune K, Hirai K, Zheng J, Tanaka R, Morikawa H (1995) Nucleotide sequence of a highly repeated DNA sequence and its chromosomal localization in Allium fistulosum. Theor Appl Genet 90:312-316

Janssen A, Colmenares SU, Karpen GH (2018) Heterochromatin: guardian of the genome. Annu Rev Cell Dev Biol. https://doi. org/10.1146/annurev-cellbio-100617-062653

Jellen EN, Leggett JM (2006) Cytogenetic manipulation in oat improvement. In: Singh RJ, Jauhar PP (eds) Genetic resources, chromosome engineering, and crop improvement: cereals. CRC Press, Boca Raton, pp 199-231

Jellen EN, Gill BS, Cox TS (1994) Genomic in situ hybridization differentiates between A/D- and C-genome chromatin and detects intergenomic translocations in polyploid oat species (genus Avena). Genome 37:613-618

Kaltsikes PJ (1973) Early seed development in hexaploid triticale. Can J Bot 51:2291-2300

Kaltsikes PJ, Roupakias DG, Thomas JB (1975) Endosperm abnormalities in Triticum - Secale combinations. I. $\times$ Triticosecale and its parental species. Can J Bot 53:2050-2067

Katsiotis A, Loukas M, Heslop-Harrison JS (2000) Repetitive DNA, genome and species relationships in Avena and Arrhenatherum (Poaceae). Ann Bot 86:1135-1142. https://doi.org/10.1006/anbo. 2000.128

Kilian A, Heller K, Kleinhofs A (1998) Development patterns of telomerase activity in barley and maize. Plant Mol Biol 37:621-628

Kosina R (1999) Selected items of wheat variation: from palaeobotany to molecular biology. Acta Soc Bot Pol 68:129-141

Kosina R, Heslop-Harrison JS (1996) Molecular cytogenetics of an amphiploid trigeneric hybrid beetwen Triticum durum, Thinopyrum distichum and Lophopyrum elongatum. Ann Bot 78:583-589 
Kosina R, Tomaszewska P (2011) Contribution on Avena (Poaceae) amphiploids endosperm. In: Frey L (ed) Advances in grass biosystematics. W. Szafer Institute of Botany, Polish Academy of Sciences, Kraków, pp 119-127

Kuipers AGJ, van Os DPM, de Jong JH, Ramanna MS (1997) Molecular cytogenetics of Alstroemeria: identification of parental genomes in interspecific hybrids and characterization of repetitive DNA families in constitutive heterochromatin. Chromos Res 5:31-39

Ladizinsky G (1998) A new species of Avena from Sicily, possibly the tetraploid progenitor of hexaploid oats. Genet Resour Crop Evol 45:263-269

Leggett JM (1998) Chromosome and genomic relationships between the diploid species Avena strigosa, A. eriantha and the tetraploid A. maroccana. Heredity 80:361-363

Leggett JM, Thomas HM, Meredith MR, Humphreys MW, Morgan WG, Thomas H, King IP (1994) Intergenomic translocations and the genomic composition of Avena maroccana Gdgr. revealed by FISH. Chromos Res 2:163-164

Leitch AR, Schwarzacher T, Mosgöller W, Bennett MD, Heslop-Harrison JS (1991) Parental genomes are separated throughout the cell cycle in a plant hybrid. Chromosoma 101:206-213

Linares C, Ferrer E, Fominaya A (1998) Discrimination of the closely related A and D genomes of the hexaploid oat Avena sativa $\mathrm{L}$. Proc Natl Acad Sci USA 95:12450-12455

Linares C, Irigoyen ML, Fominaya A (2000) Identification of $\mathrm{C}$-genome chromosomes involved in intergenomic translocations in Avena sativa L., using cloned repetitive DNA sequences. Theor Appl Genet 100:353-360

Linde-Laursen I, Jensen J (1991) Genome and chromosome disposition at somatic metaphase in a Hordeum $\times$ Psathyrostachys hybrid. Heredity 66:203-210

Liu Q, Li X, Zhou X, Li M, Zhang F, Schwarzacher T, Heslop-Harrison JS (2019) The repetitive DNA landscape in Avena (Poaceae): chromosome and genome evolution defined by major repeat classes in whole-genome sequence reads. BMC Plant Biol 19(226):1-17. https://doi.org/10.1186/s12870-019-1769-z

Lo AWI, Sabatier L, Fouladi B, Pottier G, Ricoul M, Murnane JP (2002) DNA amplification by breakage/fusion/bridge cycles initiated by spontaneous telomere loss in a human cancer cell line. Neoplasia 4:531-538

Loskutov IG (2001) Interspecific crosses in the genus Avena L. Russ J Genet 37:467-475

Lukaszewski AJ (1995) Chromatid and chromosome type breakagefusion-bridge cycles in wheat (Triticum aestivum L.). Genetics 140:1069-1085

Luo X, Tinker NA, Zhou Y, Liu J, Wan W, Chen L (2018a) A comparative cytogenetic study of 17 Avena species using Am 1 and (GAA 6 oligonucleotide FISH probes. Acta Physiol Plant 40:145. https://doi.org/10.1007/s11738-018-2721-9

Luo X, Tinker NA, Zhou Y, Wight CP, Liu J, Wan W, Chen L, Peng Y (2018b) Genomic relationships among sixteen species of Avena based on (ACT) $)_{6}$ trinucleotide repeat FISH. Genome 61:63-70. https://doi.org/10.1139/gen-2017-0132

Müller C (1909) Über karyokinetische Bilder in den Wurzelspitzen von Yucca. Jahrb Wiss Bot 47:99-117

Nikoloudakis N, Katsiotis A (2015) Comparative molecular and cytogenetic methods can clarify meiotic incongruities in Avena allopolyploid hybrids. Caryologia 68:84-91

Peña RJ, Nagarajan P, Bates LS (1982) Grain shrivelling in secondary hexaploid Triticale. II. Morphology of mature and developing grains related to grain shrivelling. Cereal Chem 59:459-468

Rajhathy T (1971) The alloploid model in Avena. Stadler Symposia 3:71-87
Rajhathy T (1991) The chromosomes of Avena. In: Gupta PK, Tsuchiya $\mathrm{T}$ (eds) Chromosome engineering in plants: genetics, breeding, evolution. Elsevier, Amsterdam, pp 449-467

Rajhathy T, Thomas H (1972) Genetic control of chromosome pairing in hexaploid oats. Nat New Biol 239:217-219

Santos-Serejo JA, Aguiar-Perecin MLR (2016) Breakage-fusionbridge cycles and de novo telomere formation on broken chromosomes in maize callus cultures. Genome. https://doi.org/10. 1139/gen-2015-0211

Schubert I, Lysak MA (2011) Interpretation of karyotype evolution should consider chromosome structural constraints. Trends Genet 27:207-216

Schwarzacher T, Heslop-Harrison P (2000) Practical in situ hybridization. Bios Scientific Publishers Ltd, Oxford

Schwarzacher T, Leitch AR, Bennett MD, Heslop-Harrison JS (1989) In situ localization of parental genomes in a wide hybrid. Ann Bot 64:315-324

Seijo G, Lavia GI, Fernández A, Krapovickas A, Ducasse DA, Bertioli DJ, Moscone EA (2007) Genomic relationships between the cultivated peanut (Arachis hypogaea, Leguminosae) and its close relatives revealed by double GISH. Am J Bot 94:1963-1971

Shelukhina OY, Badaeva ED, Loskutov IG, Pukhalsky VA (2007) A comparative cytogenetic study of the tetraploid oat species with the $\mathrm{A}$ and $\mathrm{C}$ genomes: Avena insularis, A. magna, and A. murphyi. Russ J Genet 43:613-626

Siroky J, Zluvova J, Riha K, Shippen DE, Vyskot B (2003) Rearrangements of ribosomal DNA clusters in late generation telomerasedeficient Arabidopsis. Chromosoma 112:116-123. https://doi.org/ 10.1007/s00412-003-0251-7

Świetlikowska M (2008) Zmienność mikrostrukturalna i cytogenetyczna amfiploida Avena magna $\times$ A. longiglumis. Dissertation, University of Wrocław.

Thomas H, Al-Ansari N (1980) Genotypic control of chromosome pairing in Avena longiglumis $\times$ A. sativa hybrids. Chromosoma 79:115-124

Tomaszewska P (2017) Mikrostrukturalna i cytogenetyczna analiza bielma wybranych międzygatunkowych amfiploidów rodzaju Avena L. Dissertation, University of Wrocław.

Tomaszewska P, Kosina R (2013) On the different role of parental genomes in selected hybrid grasses. Eur Cytogenet Conf 21(Suppl 1):131-132

Tomaszewska P, Kosina R (2018) Instability of endosperm development in amphiploids and their parental species in the genus Avena L. Plant Cell Rep 37:145-158

Ueno M, Morikawa T (2007) Production of synthetic polyploid oats and detection of $\mathrm{C}$ genome rearrangements by GISH and FISH. Breed Sci 57:339-343

Yan H, Bekele WA, Wight CP, Peng Y, Langdon T, Latta RG, Fu Y-B, Diederichsen A, Howarth CJ, Jellen EN, Boyle B, Wei Y, Tinker NA (2016) High-density marker profiling confirms ancestral genomes of Avena species and identifies D-genome chromosomes of hexaploid oat. Theor Appl Genet 129:2133-2149

Yan H, Ren Z, Deng D, Yang K, Yang C, Zhou P, Wight CP, Ren C, Peng Y (2021) New evidence confirming the CD genomic constitutions of the tetraploid Avena species in the section Pachycarpa Baum. PLoS ONE 16:e0240703. https://doi.org/10.1371/journal. pone. 0240703

Yang Q, Hanson L, Bennett MD, Leitch IJ (1999) Genome structure and evolution in the allohexaploid weed Avena fatua L. (Poaceae). Genome 42:512-518

Publisher's Note Springer Nature remains neutral with regard to jurisdictional claims in published maps and institutional affiliations. 